\title{
Uma Heurística ILS para Resolução do Problema de Carregamento e Descarregamento de Contêineres em Navios Porta-contêineres
}

\author{
Amaro José de S. Neto ${ }^{1}$, Dalessandro S. Vianna ${ }^{2}$, Marcilene de Fátima D. Vianna ${ }^{3}$ \\ ${ }^{1}$ Universidade Candido Mendes (UCAM-Campos) \\ Rua Anita Pessanha, 100, Parque São Caetano, Campos dos Goytacazes-RJ. 28040-320.
}

${ }^{2}$ Departamento de Ciência e Tecnologia - RCT

Universidade Federal Fluminense, Pólo Universitário Rio das Ostras - UFF/PURO

Rua Recife, s/n, Jardim Bela Vista, Rio das Ostras-RJ. 22890-000.

${ }^{3}$ Departamento Fundamentos de Ciência e Sociedade - SFC

Universidade Federal Fluminense, Pólo de Campos dos Goytacazes - UFF/PUCG

Rua Recife, s/n, Jardim Bela Vista, Rio das Ostras-RJ. 22890-000.

amaro.neto@gmail.com, dalessandro@pq.cnpq.br, marcilenedianin@vm.uff.br

\begin{abstract}
When docking at a port terminal it may be necessary to perform various operations of loading and unloading containers. Sometimes, when unloading, the target container which needs to be unloaded may be positioned below other containers that will not be unloaded at this time. These ones need to be removed to unload the target container. The goal is to find the best loading sequence minimizing thus the number of "rearrangements". The proposed heuristic was compared with a greedy heuristic and a local search method. The results show the adequacy of ILS heuristic to the problem addressed.
\end{abstract}

Resumo: Ao atracar em um terminal portuário pode ser necessário realizar diversas operações de carregamento e descarregamento de contêineres. Algumas vezes, no descarregamento, o contêiner alvo que necessita ser desembarcado pode estar posicionado abaixo de outros contêineres que não serão descarregados neste momento. Estes precisarão ser removidos para descarregar o contêiner alvo. O objetivo é encontrar a melhor sequência de carregamento, minimizando, desta forma, o número de "remanejos". A heurística proposta foi comparada com uma heuristica gulosa e um método de busca local. Os resultados obtidos mostram adequação da heurística ILS ao problema abordado.

Palavras-chave: Otimização; Carregamento; Contêineres; Metaheurísticas; ILS.

\section{Introdução}

Os navios porta-contêineres são embarcações especializadas em transporte de carga conteinerizada. Estas embarcações dispõem de espaços celulares (baias), onde os contêineres são empilhados (ver Figura 1). A movimentação da carga ocorre tanto nas baias quanto no convés do navio através de equipamentos de bordo ou de terra (GÓES, 
2002). Devido à estrutura do navio e a forma que a carga deve estar disposta, o acesso aos contêineres é feito pelo topo da pilha. Pode ser necessário movimentar alguns contêineres para descarregar outros que estão numa posição inferior. A essa operação dá se o nome remanejo.

Terminais Concentradores são portos que têm a finalidade de atender à concentração de cargas (conteinerizada) de toda uma região para posterior distribuição para outros portos. (BERTOLANI; LEME, 2004). Sua eficiência está relacionada à ordenação e forma de lidar com os contêineres (SOBRAL et al., 2009). Um navio portacontêineres pode atracar em terminais concentradores para realizar diversas operações de carga e descarga de contêineres. Existem dois critérios fundamentais no problema de planejamento de estiva: a minimização do número de remanejos e as restrições de estabilidade.
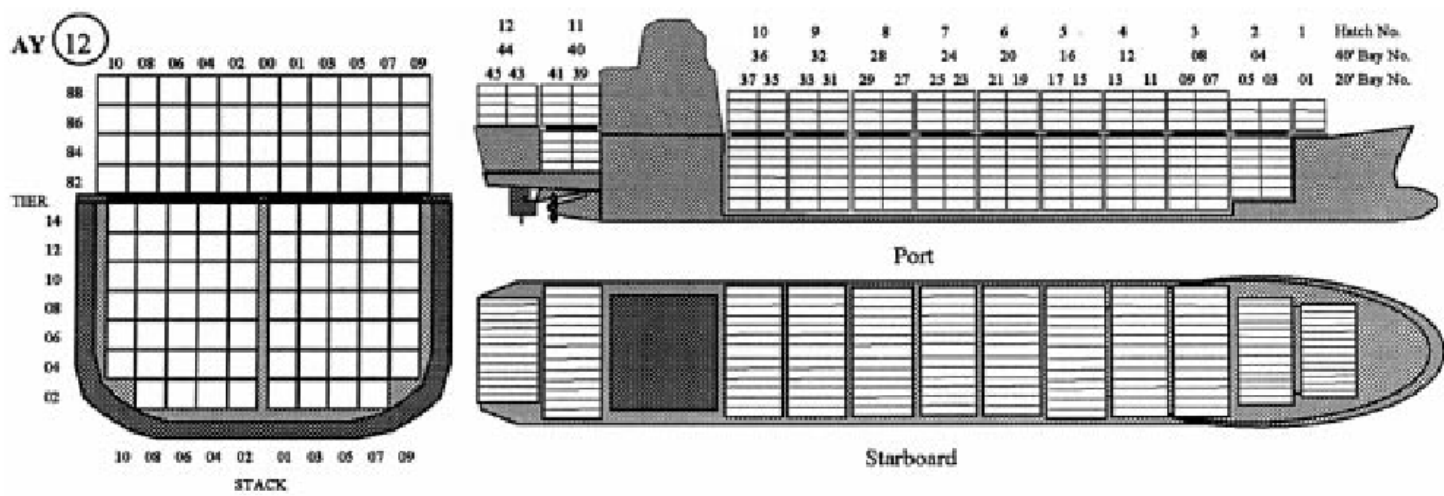

Figura 1. Estrutura de um navio. Fonte: Wilson e Roach (2000)

Neste artigo o foco é a embarcação porta-contêiner. É discutida a posição onde as cargas são armazenadas no navio, de modo que em cada porto, mesmo necessitando realizar operações de carregamento e descarregamento de contêineres, o número de remanejos seja o menor possível. De acordo com Avriel et al. (2000), este problema é NP-Completo.

O objetivo deste trabalho é desenvolver uma heurística ILS (Iterated Local Search) para o problema de carregamento e descarregamento de contêineres em um navio porta-contêiner, visando minimizar o número de remanejos.

$\mathrm{Na}$ literatura podem ser encontrados trabalhos que abordam problemas semelhantes ao tratado neste trabalho. Dentre estes, pode-se citar:

- Sobral et al. (2009) desenvolveram um algoritmo Beam Search para Resolução do problema de carregamento e descarregamento de contêineres em terminais portuários;

- Campos (2008) elaborou um estudo sobre a integração entre carregamento e roteamento de veículos;

- Morabito e Arenales (1997) mostraram diferentes abordagens para o problema de carregamento de contêineres;

- Raidl (1999) propôs um algoritmo genético para o problema de empacotamento de múltiplos contêineres.

- Martins et al. (2009) estudaram o problema de estocagem de contêineres; e 
- Azevedo (2009) propôs um algoritmo genético para resolver o problema de carregamento e descarregamento de contêineres em terminais portuários.

O restante do trabalho está organizado da seguinte maneira: na Seção 2 é apresentado o problema a ser resolvido. Na Seção 3 é mostrada a representação da demanda de contêineres, da baia e da solução, além da função de avaliação. Na Seção 4 é apresentada a metaheurística ILS desenvolvida. Na Seção 5 são apresentados os resultados computacionais obtidos e na Seção 6 as conclusões.

\section{Apresentação do problema}

Os navios porta-contêineres são embarcações de grande porte possuem uma estrutura celular que facilita a manipulação da carga armazenada em contêineres. As células são agrupadas por seções (baias), onde contêineres podem ser empilhados. Possui uma rota $R=\left\{p_{0}, p_{1}, p_{2}, \ldots, p_{n}\right\}$ que é conhecida antes de sua partida. Geralmente são circulares, partindo de um Porto $p_{0}$, percorrendo todos os Portos $p_{i}$, descarregando as cargas nos portos de destino e carregando novas cargas destinadas a outros portos, e ao fim retorna ao Porto $p_{0}$. Cada um dos portos $p$ que compõe $R$ tem uma demanda de contêineres que necessitarão ser carregados na embarcação. Além disto, o navio possui uma capacidade que é medida em TEU (Twenty-foot Equivalent Units). Por exemplo, uma embarcação com capacidade de 1000 TEUs pode armazenar 1000 contêineres de 20 pés.

Ao atracar em um Porto $p_{i}$, o navio primeiro efetuará o descarregamento de contêineres destinados a $p_{i}$, caso haja. Nesta operação, pode ser necessário descarregar temporariamente os contêineres que estão armazenados numa pilha de uma determinada baia do navio, para conseguir descarregar um contêiner que está localizado em uma posição inferior desta pilha. Posteriormente, caso haja demanda, os contêineres serão carregados do terminal para o navio, isto implica numa sequência de carregamento $S=$ $\left\{c_{0}, c_{1}, c_{2}, \ldots, c_{\mathrm{n}}\right\}$ para cada porto que o navio irá atracar, onde deve ser buscado um melhor arranjo destas sequências de forma a minimizar o número de remanejos para os portos seguintes.

\section{Representação}

Nesta seção será discutida a representação da demanda de contêineres, da baia, da solução e também a função de avaliação.

\begin{tabular}{|c|c|c|c|c|c|}
\hline & & & & & \\
\hline & 1 & 2 & 3 & 4 & 5 \\
\hline 1 & 0 & 2 & 4 & 2 & 4 \\
\hline 2 & 5 & 0 & 0 & 4 & 0 \\
\hline 3 & 0 & 2 & 0 & 2 & 6 \\
\hline 4 & 6 & 0 & 0 & 0 & 0 \\
\hline 5 & 0 & 6 & 0 & 4 & 0 \\
\hline
\end{tabular}

Figura 3. Exemplo de uma matriz de transporte de um navio

\subsection{Demanda de contêineres}

A representação da demanda de contêineres será através de uma matriz de transporte $T_{o d}$, onde $o=1,2, \ldots, N$ e $d=1,2, \ldots, N$ ( $N$ é o número de portos). Considere $o$ sendo o porto de origem, e $d$ o porto de destino. $\mathrm{O}$ número na posição $T_{o d}$ corresponde a 
quantidade de contêineres que deverão ser carregados no Porto $o$ para posteriormente serem descarregados no Porto $d$, ou seja, as demandas correspondentes. Na Figura 3 é mostrado um exemplo de uma matriz de transporte. Por exemplo, quando o navio atracar no Porto 2, será necessário carregar $T_{21}=5$ contêineres que têm como destino o Porto 1 e $T_{24}=4$ contêineres com destino ao Porto 4 .

\subsection{Baia}

Uma baia será representada computacionalmente por uma matriz de ocupação $\mathrm{O}_{l c}$, onde $l=1,2, \ldots, L$ e $c=1,2, \ldots, H$ (onde $\mathrm{L}$ e $\mathrm{H}$ significam quantos contêineres cabem na largura e na altura do navio respectivamente). Nela serão registradas suas posições $(l, c)$ livres e ocupadas. Em cada célula $O_{l c}$ ocupada, o valor inteiro corresponde ao destino em que a carga deverá ser entregue. $O_{l c}=0$ significa que a posição $(l, c)$ da matriz está livre. A simplicidade desta representação facilita à compreensão do armazenamento, assim como a manipulação dos itens. Veja no exemplo da Figura 4, o valor na posição $(1,1)=$ 0 , o que significa que esta posição está livre e pronta para receber alguma carga. Enquanto na posição $(3,2)=3$, corresponde ao porto no qual o contêiner da posição $(3,2)$ deverá ser descarregado, neste caso o Porto 3.

\begin{tabular}{l|l|l|l|}
\multicolumn{1}{c}{} & \multicolumn{1}{|c|}{2} & \multicolumn{1}{c}{3} \\
\cline { 2 - 4 } 1 & 0 & 5 & 0 \\
\cline { 2 - 4 } 2 & 0 & 3 & 3 \\
\cline { 2 - 4 } 3 & 2 & 3 & 2 \\
\cline { 2 - 4 } & & &
\end{tabular}

Figura 4. Exemplo da representação da baia de um navio com capacidade de 9 contêineres.

Quando ocorre a atracação do navio em um porto, ocorrem operações de carregamento e descarregamento de contêineres. Devido à estas operações as informações nesta matriz de ocupação são atualizadas constantemente. A cada porto atracado, será necessário pelo menos uma destas operações, caso contrário a atracação não ocorreria.

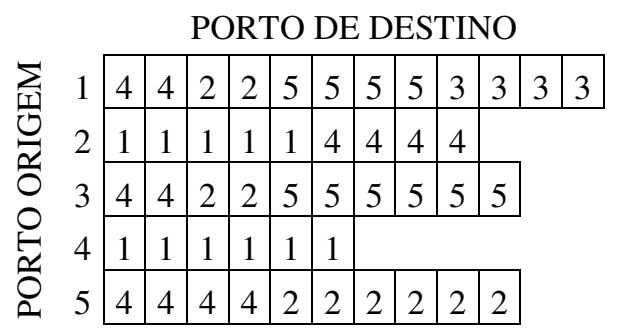

Figura 5. Representação de uma solução

\subsection{Solução}

Neste trabalho, uma solução é representada por uma lista, com o tamanho determinado pelo número de portos. Cada posição $i$ da lista armazena um vetor que possui as demandas que devem ser embarcadas no Porto $i$. Cada vetor é uma sequência de carregamento, onde o primeiro item será o primeiro a ser armazenado no navio, e assim sucessivamente. A Figura 5 ilustra uma solução para um problema com 5 portos. A demanda considerada será a mesma da Figura 3. Suponha a rota de visitação do navio: 1-3-5-2-4-1. Cada posição do vetor corresponde a um contêiner, e o número contido em cada uma destas posições refere-se ao porto que o contêiner deve ser descarregado. Por exemplo, quando a embarcação atracar no Porto 5, de acordo com a respectiva 
sequência, primeiramente serão carregados no navio 4 contêineres com destino ao Porto 4, em seguida serão carregados 6 contêineres destinados ao Porto 2.

Tabela 1. Execução da função de avaliação

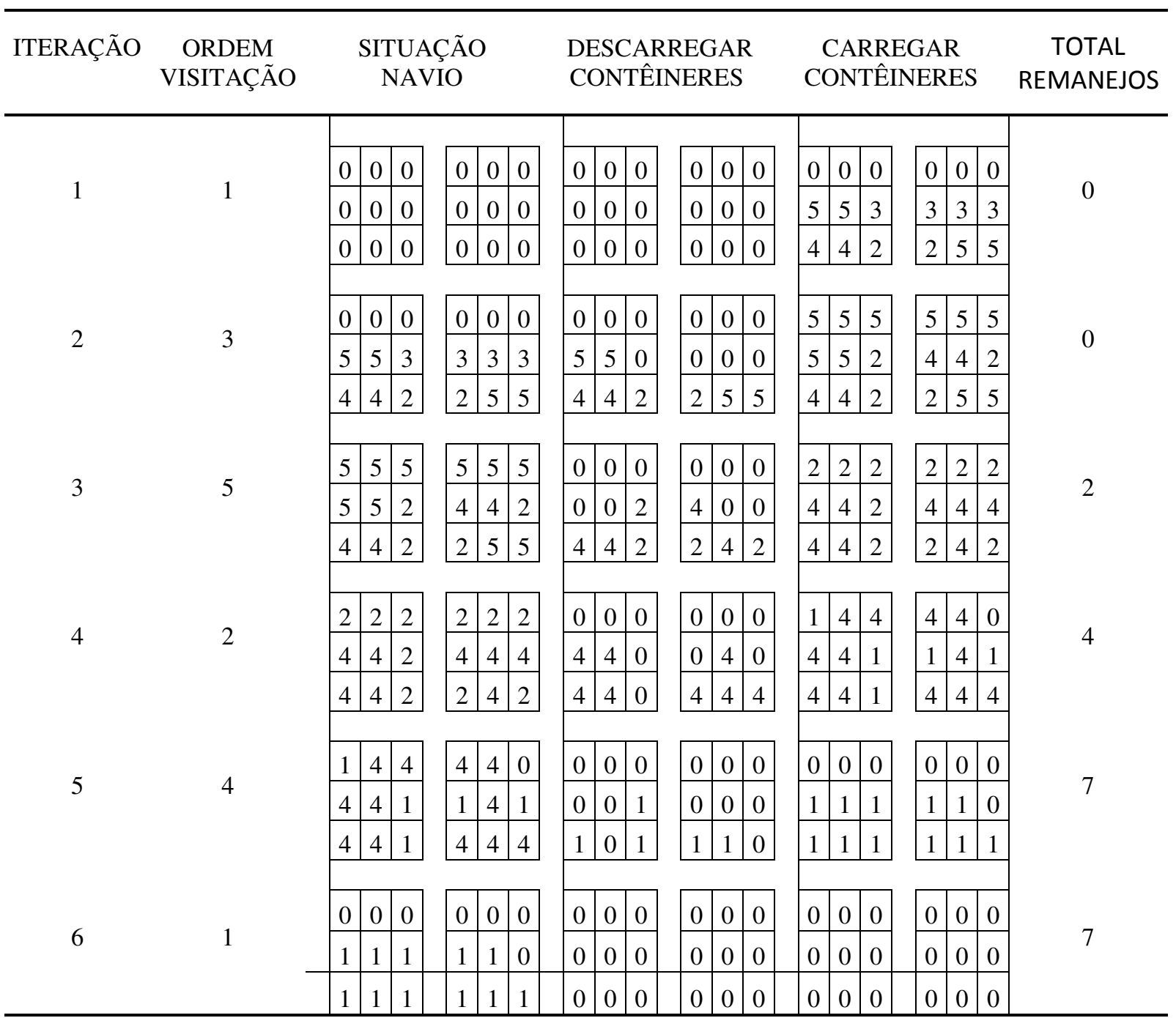

\subsection{Função de Avaliação}

O objetivo principal do problema proposto é minimizar o número de remanejos. Para isto, a função que irá avaliar o problema terá como entrada a lista de sequências de carregamento (solução). Ao término, será retornado o número total de remanejos efetuados, através da simulação do cumprimento de um determinado trajeto, realizando descarregamentos e carregamentos, quando necessários, de acordo com as respectivas sequências de carregamento. Um exemplo desta função é mostrado pela Tabela 1, a qual utiliza como dado de entrada a solução descrita na Figura 5 e que possui duas baias de tamanho 3x3 ( $\mathrm{LxH}$, onde L e H significam quantos contêineres cabem na largura e na altura do navio respectivamente). Por exemplo, na iteração 1, de acordo com a ordem de visitação, o navio atracará no Porto 1 e encontra-se vazio. Como não há contêineres a serem descarregados, é feito o carregamento de 2 contêineres com destino para o Porto 4, 2 com destino para o Porto 2, 4 com destino para o Porto 5 e 4 com destino para o Porto 3. Na iteração 2, o navio está parcialmente ocupado e atracado no Porto 3. É feito 
o descarregamento de 4 contêineres que tinham como destino o Porto 3 , e em seguida realiza-se o carregamento. Na iteração 3 o navio está totalmente ocupado e atracado no Porto 5. Será feito o descarregamento de contêineres com destino ao Porto 5, mas como pode ser observado, na baia 2 existem contêineres que precisam ser descarregados e estão no fundo da baia e com contêineres sobre eles. Será necessário descarregar esses contêineres numa pilha auxiliar para então descarregar os contêineres que têm como destino o Porto 5. Computa-se o número de remanejos $=2$, e então inicia-se o processo de carregamento e o navio fica totalmente ocupado. Este processo é repetido ao longo de todo o trajeto de visitação.

\section{Heurística ILS proposta}

A Metaheurística ILS (Iterated Local Search) é um método de busca local que procura em um subespaço do espaço de busca de soluções, definido por soluções que são ótimas locais de determinado procedimento de otimização (LOURENÇO et al., 2002). Existem 5 pontos importantes para o funcionamento do algoritmo: a geração de uma solução de partida; o procedimento de perturbação; o procedimento de busca local; o critério de parada; e o critério de aceitação. Primeiramente é realizada uma busca local na solução de partida $s$ (gerada após método de construção guloso), posteriormente $s$ será perturbada e realizada uma busca local gerando uma nova solução $s^{\prime \prime}$ e caso seja mais apta que $s$ passará a ser a nova solução de partida e o processo de perturbação e busca local se repete até um critério de parada seja satisfeito. A solução mais apta encontrada ao longo de todas as iterações ILS é retornada como resultado.

O sucesso do uso da metaheuristica ILS em problemas de otimização é descrito em diversos trabalhos da literatura, dentre os quais pode se citar: (TEMPONI, 2007), (SOUZA FILHO, 2008), e (MESQUITA, 2010).

Nas próximas subseções serão apresentadas as etapas da heurística proposta. As subseções 4.1 e 4.2 e 4.3 apresentam as fases de construção, de perturbação e de busca local, respectivamente.

\subsection{Fase de construção}

Esta fase tem como objetivo prover uma solução factível e de boa qualidade para a fase de busca local. A solução será construída iterativamente, elemento por elemento. Para cada porto são selecionados todos os contêineres que devem ser carregados. Em seguida, são ordenados numa lista de forma que os contêineres destinados ao porto mais distante no trajeto de visitação ficarão como primeiros na sequência (critério guloso).

Na Tabela 2 é mostrado o algoritmo de construção de uma solução. O laço que vai da linha 1 até 9 garante que será montada uma sequência de carregamento para cada porto. O laço que vai da linha 3 até 8 garante a montagem da sequência na ordem inversa a de visitação, ou seja, os contêineres destinados aos portos mais distantes no trajeto de visitação serão colocados como primeiros na lista. O laço que vai da linha 4 até 7 garante que todas as demandas serão colocadas na sequência de carregamento. Na linha 5 é montada a sequência de carregamento de cada porto, para então na linha 10 retornar à solução completa.

Na Figura 6 é ilustrada à construção de uma solução. Considere que o navio visitará 3 portos, sua ordem de visitação é 1-3-2-1. Observe que na montagem da ordem de carregamento do Porto 1, primeiro são selecionadas as cargas que têm como destino 
o porto que será visitado por último. De acordo com a ordem de visitação, o último é o Porto 1, mas como a sequência em construção pertence ao Porto 1, não teria sentido este porto ter demanda de carregamento para ele mesmo. Então o Porto 2 tem sua demanda selecionada e colocada como os primeiros contêineres que serão carregados da sequência. Em seguida, seleciona-se a demanda do porto que será visitado antes do Porto 2, neste caso, o Porto 3, que têm sua demanda selecionada e colocada na sequência também. A montagem das sequências para os outros portos segue a mesma lógica.

Tabela 2. Algoritmo de construção de uma solução

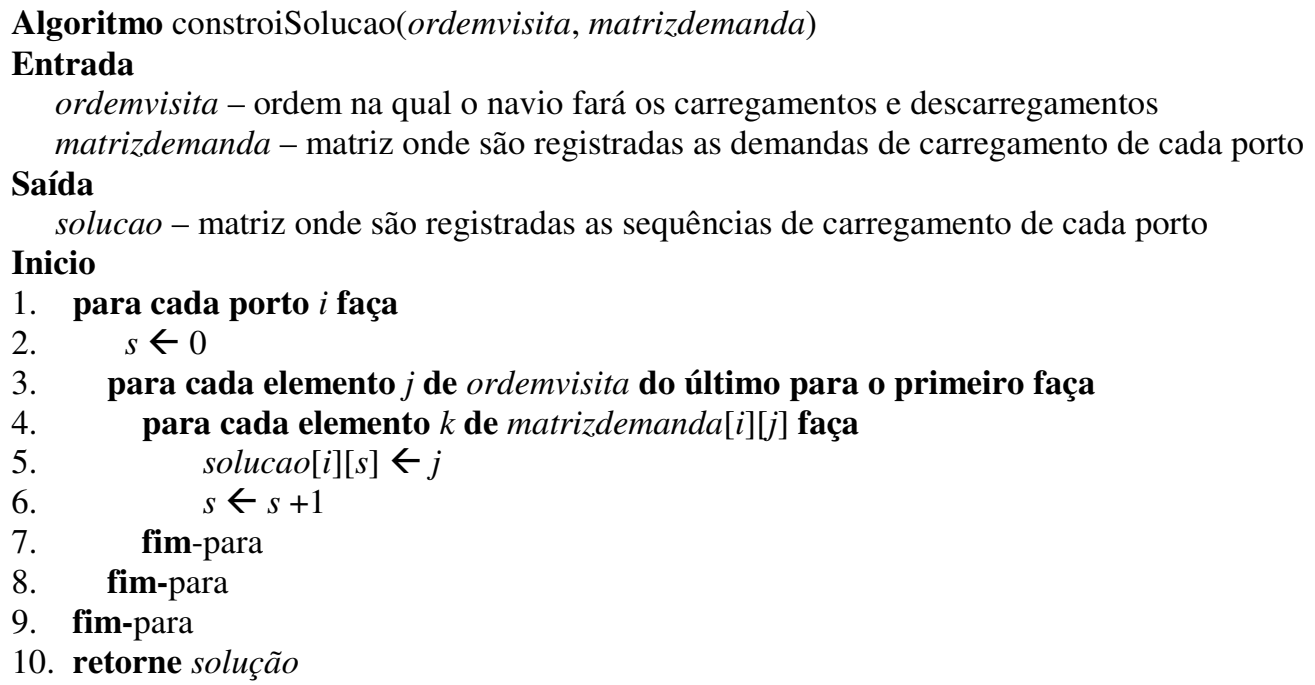

Matriz demanda Construindo uma solução

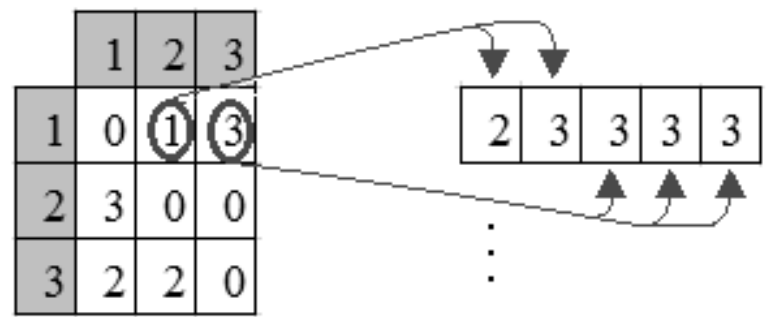

Figura 6. Montagem de uma solução

\subsection{Fase de perturbação}

Esta fase tem como objetivo prover mudanças em uma solução. A perturbação considerada consiste em efetuar $r$ trocas em cada sequência de carregamento, a escolha dos contêineres trocados é aleatória. O nível perturbação deve ser controlado, pois fortes perturbações podem implicar em reinício aleatório, e perturbações demasiadamente fracas podem reduzir as chances de encontrar novas soluções.

\subsection{Fase de busca local}

O objetivo desta fase é possibilitar uma melhoria para a solução construída através da busca em uma vizinhança por uma solução de melhor qualidade. 
A vizinhança é o conjunto de soluções próximas a solução inicial que pode ser obtida por um movimento, onde o algoritmo de busca local poderá procurar por uma solução melhor. Neste trabalho, o movimento consiste em trocar nas sequências de carregamento, um contêiner de uma determinada posição por um outro na mesma sequência em posição diferente. Com a troca realizada, a respectiva sequência é alterada e reavaliada, para assim, obter seu número de remanejos.

A Tabela 3 mostra o algoritmo de busca local. O laço que vai da linha 2 até 14 garante que as sequências de cada porto serão contempladas com a troca. O laço que vai da linha 3 até 13 irá percorrer toda a sequência. O laço que vai da linha 4 até 10 fará com que se busque na sequência a próxima posição para efetuar a troca. Na linha 5 e 6 , é realizada a troca e a avaliação, respectivamente. O bloco delimitado pela linha 7 e 11 serve para verificar se a troca gerou uma solução melhor; caso contrário desfaz a troca e a solução volta a seu estado anterior.

Tabela 3. Algoritmo de busca local

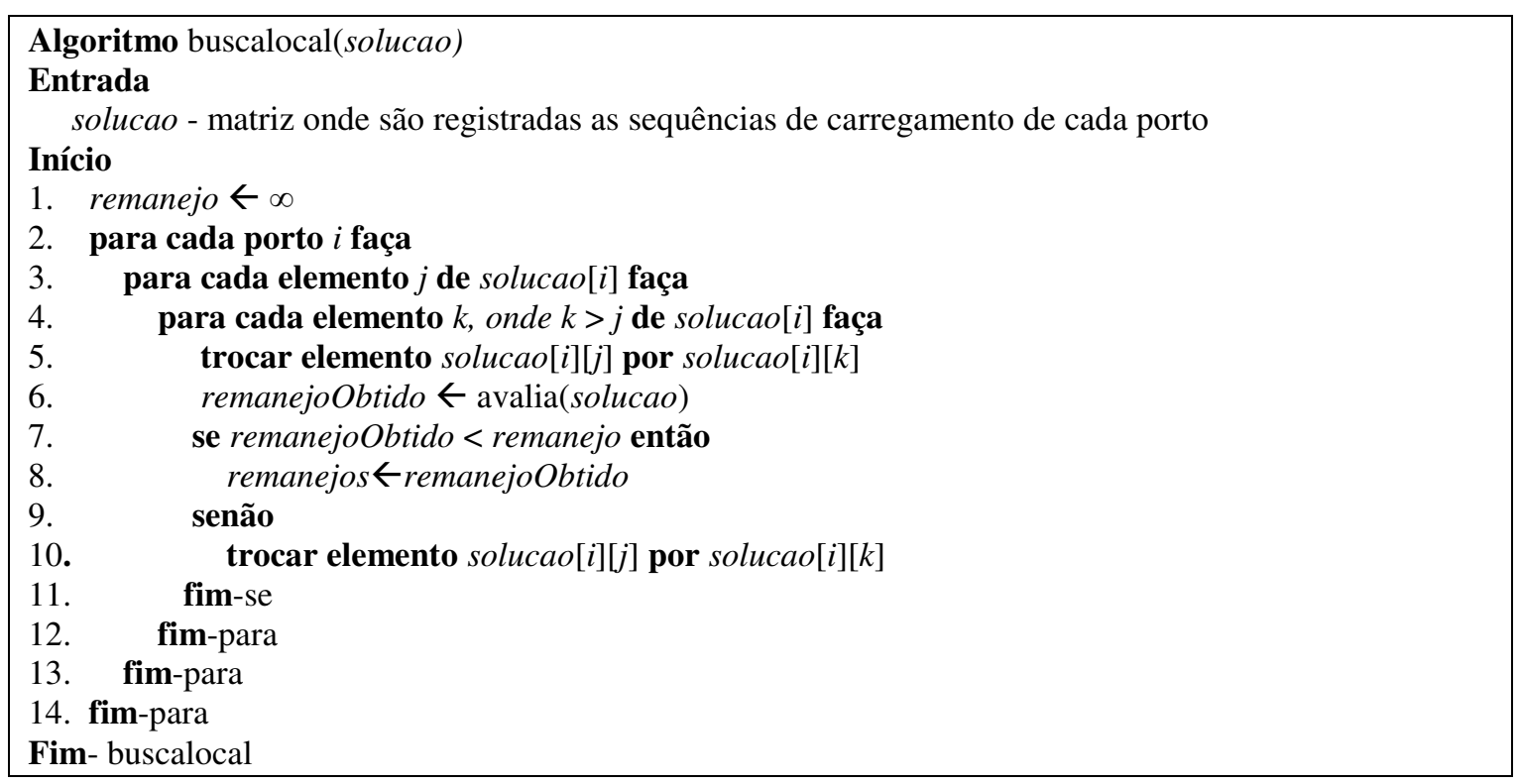

\section{Resultados}

Por questões de balanceamento do navio, o atendimento a uma determinada demanda de carregamento será de acordo com o menor valor entre a disponibilidade da baia selecionada e o bloco máximo de contêineres que pode ser atendido por uma baia. A baia selecionada é a que detém o menor número de contêineres armazenados. Para calcular o bloco máximo é necessário que seja determinado o número de camadas da baia que pode ser preenchido sem comprometer o balanceamento da embarcação. $O$ bloco é obtido a partir do número de camadas x largura da baia. Neste trabalho foi considerado que o número de camadas é a metade da altura. Por exemplo, um navio com 2 baias que suportam 7 contêineres na largura $L$ e 18 na altura $H$ ( $L$ e $H$ são dados de entrada do algoritmo), teria o número de camadas igual a 9 e o bloco máximo seria de 63 .

Sobre a carga que será carregada e descarregada, não é considerado seu peso e são supostas cargas homogêneas, ou seja, com o mesmo tamanho. 
Foram geradas 18 instâncias, considerando navios com capacidade de 600 a 2400 TEUs (Twenty-foot Equivalent Units), com visitação para 10, 15, e 20 portos, totalizando 54. Estas instâncias têm as seguintes informações: número de portos, número de baias do navio, a dimensão $(L x H)$ das baias, a ordem de visitação do navio e a demanda que o navio deve atender em cada porto. Foi considerado que as demandas dos portos não excedem a capacidade do navio.

O ILS tem como entrada uma solução inicial obtida através de um método construtivo guloso. Para avaliar o desempenho dos resultados do algoritmo proposto, foi usado como parâmetro de comparação o número de remanejos obtidos com o método construtivo puramente guloso (construtivo) e o construtivo puramente guloso seguido da busca local. Na perturbação foi considerado $r$ movimentos $=2$. e o número de iterações do ILS foi de 20 iterações. Estes parâmetros foram determinados empiricamente.

Os algoritmos foram desenvolvidos na linguagem de programação $\mathrm{C}$ e executado em um computador Core 2 Duo 2.0, com 2 GB de memória RAM no sistema operacional Windows XP. As Tabelas 4, 5 e 6 mostram os resultados dos algoritmos após uma execução de cada algoritmo. Conforme pode ser observado, o algoritmo ILS se mostrou superior ao método puramente guloso em todos os casos testados. Em relação ao construtivo seguido da busca local, o ILS somente não obteve melhora no teste número 17 da tabela 6. A média percentual de melhora do ILS em relação à construção encontrada foi de $29 \%$. Houve casos em que a diferença percentual de melhora entre o ILS e o construtivo seguido da busca local foi superior a $15 \%$, como pode ser visto no teste de número 10 da Tabela 4 .

Tabela 4. Resultados obtidos para instâncias com 10 portos

\begin{tabular}{|c|c|c|c|c|c|c|c|c|c|c|c|c|}
\hline \multirow{2}{*}{$\mathrm{N}^{\mathrm{o}}$} & \multicolumn{3}{|c|}{ BAIA } & \multirow{2}{*}{ TEUs } & \multicolumn{2}{|c|}{ CONSTRUTIVO } & \multicolumn{3}{|c|}{ BUSCA LOCAL } & \multicolumn{3}{|c|}{ ILS } \\
\hline & Q & $\mathrm{L}$ & $\mathrm{H}$ & & CUSTO & TEMPO & CUSTO & $\%$ & TEMPO & CUSTO & $\%$ & TEMPO \\
\hline 1 & 12 & 5 & 10 & 600 & 558 & 0 & 470 & $16 \%$ & 1,6 & 408 & $27 \%$ & 40,23 \\
\hline 2 & 12 & 7 & 10 & 840 & 979 & 0 & 674 & $31 \%$ & 3,73 & 624 & $36 \%$ & 86,57 \\
\hline 3 & 12 & 10 & 10 & 1200 & 945 & 0 & 721 & $24 \%$ & 6,89 & 751 & $21 \%$ & 155,03 \\
\hline 4 & 12 & 5 & 13 & 780 & 1713 & 0 & 1444 & $16 \%$ & 8,87 & 1338 & $22 \%$ & 283,59 \\
\hline 5 & 12 & 7 & 13 & 1092 & 835 & 0 & 544 & $35 \%$ & 3,28 & 528 & $37 \%$ & 71,57 \\
\hline 6 & 12 & 10 & 13 & 1560 & 1569 & 0 & 1299 & $17 \%$ & 13,23 & 1196 & $24 \%$ & 311,45 \\
\hline 7 & 12 & 5 & 15 & 900 & 777 & 0 & 638 & $18 \%$ & 3,57 & 573 & $26 \%$ & 90,71 \\
\hline 8 & 12 & 7 & 15 & 1260 & 1024 & 0 & 708 & $31 \%$ & 7,04 & 679 & $34 \%$ & 158,06 \\
\hline 9 & 12 & 10 & 15 & 1800 & 1489 & 0 & 992 & $33 \%$ & 15,51 & 882 & $41 \%$ & 325,73 \\
\hline 10 & 16 & 5 & 10 & 800 & 809 & 0 & 652 & $19 \%$ & 3,12 & 540 & $33 \%$ & 74,62 \\
\hline 11 & 16 & 7 & 10 & 1120 & 1169 & 0 & 805 & $31 \%$ & 6,68 & 650 & $44 \%$ & 147,21 \\
\hline 12 & 16 & 10 & 10 & 1600 & 993 & 0 & 695 & $30 \%$ & 10,62 & 679 & $32 \%$ & 249,9 \\
\hline 13 & 16 & 5 & 13 & 1040 & 1352 & 0 & 1165 & $14 \%$ & 6,17 & 1053 & $22 \%$ & 147,57 \\
\hline 14 & 16 & 7 & 13 & 1456 & 1303 & 0 & 985 & $24 \%$ & 9,95 & 937 & $28 \%$ & 233,71 \\
\hline 15 & 16 & 10 & 13 & 2080 & 1665 & 0 & 1456 & $13 \%$ & 25,48 & 1272 & $24 \%$ & 563,73 \\
\hline 16 & 16 & 5 & 15 & 1200 & 1130 & 0 & 888 & $21 \%$ & 7,82 & 865 & $23 \%$ & 168,09 \\
\hline 17 & 16 & 7 & 15 & 1680 & 1302 & 0 & 924 & $29 \%$ & 13,5 & 870 & $33 \%$ & 295,53 \\
\hline 18 & 16 & 10 & 15 & 2400 & 3899 & 0 & 3042 & $22 \%$ & 40,96 & 2593 & $33 \%$ & 926,34 \\
\hline
\end{tabular}


Tabela 5. Resultados obtidos para instâncias com 15 portos

\begin{tabular}{|c|c|c|c|c|c|c|c|c|c|c|c|c|}
\hline \multirow{2}{*}{$\mathrm{N}^{\mathrm{o}}$} & \multicolumn{3}{|c|}{ BAIA } & \multirow{2}{*}{ TEUs } & \multicolumn{2}{|c|}{ CONSTRUÇÃO } & \multicolumn{3}{|c|}{ BUSCA LOCAL } & \multicolumn{3}{|c|}{ ILS } \\
\hline & $\mathrm{Q}$ & \begin{tabular}{|l|l}
$\mathrm{L}$ \\
\end{tabular} & $\mathrm{H}$ & & CUSTO & TEMPO & CUSTO & $\%$ & TEMPO & CUSTO & $\%$ & TEMPO \\
\hline 1 & 12 & 5 & 10 & 600 & 1191 & 0 & 941 & $21 \%$ & 4,25 & 843 & $29 \%$ & 98,12 \\
\hline 2 & 12 & 7 & 10 & 840 & 1263 & 0 & 994 & $21 \%$ & 7,14 & 890 & $30 \%$ & 156,04 \\
\hline 3 & 12 & 10 & 10 & 1200 & 1502 & 0 & 1153 & $23 \%$ & 13,98 & 1091 & $27 \%$ & 324,75 \\
\hline 4 & 12 & 5 & 13 & 780 & 1191 & 0 & 941 & $21 \%$ & 4,23 & 865 & $27 \%$ & 95,45 \\
\hline 5 & 12 & 7 & 13 & 1092 & 1716 & 0 & 1322 & $23 \%$ & 13,96 & 1234 & $28 \%$ & 310,56 \\
\hline 6 & 12 & 10 & 13 & 1560 & 2506 & 0 & 1804 & $28 \%$ & 30,01 & 1689 & $33 \%$ & 653,65 \\
\hline 7 & 12 & 5 & 15 & 900 & 1924 & 0 & 1472 & $23 \%$ & 16,15 & 1398 & $27 \%$ & 337,43 \\
\hline 8 & 12 & 7 & 15 & 1260 & 3089 & 0 & 2379 & $23 \%$ & 22,34 & 2140 & $31 \%$ & 515,04 \\
\hline 9 & 12 & 10 & 15 & 1800 & 2497 & 0 & 2041 & $18 \%$ & 32,81 & 1869 & $25 \%$ & 773,37 \\
\hline 10 & 16 & 5 & 10 & 800 & 1174 & 0 & 859 & $27 \%$ & 7,25 & 806 & $31 \%$ & 155,01 \\
\hline 11 & 16 & 7 & 10 & 1120 & 1648 & 0 & 1120 & $32 \%$ & 12,84 & 1049 & $36 \%$ & 298,7 \\
\hline 12 & 16 & 10 & 10 & 1600 & 2659 & 0 & 1647 & $38 \%$ & 26,43 & 1547 & $42 \%$ & 604,15 \\
\hline 13 & 16 & 5 & 13 & 1040 & 2078 & 0 & 1615 & $22 \%$ & 13,57 & 1552 & $25 \%$ & 351,59 \\
\hline 14 & 16 & 7 & 13 & 1456 & 2291 & 0 & 1769 & $23 \%$ & 26,92 & 1693 & $26 \%$ & 630,35 \\
\hline 15 & 16 & 10 & 13 & 2080 & 2706 & 0 & 2035 & $25 \%$ & 51,14 & 1898 & $30 \%$ & 1156,75 \\
\hline 16 & 16 & 5 & 15 & 1200 & 1682 & 0 & 1256 & $25 \%$ & 14,93 & 1225 & $27 \%$ & 339,35 \\
\hline 17 & 16 & 7 & 15 & 1680 & 2383 & 0 & 1893 & $21 \%$ & 31,59 & 1740 & $27 \%$ & 680,21 \\
\hline 18 & 16 & 10 & 15 & 2400 & 3895 & 0 & 3141 & $19 \%$ & 68,98 & 2800 & $28 \%$ & 1498,1 \\
\hline
\end{tabular}

Tabela 6. Resultados obtidos para instâncias com 20 portos

\begin{tabular}{|c|c|c|c|c|c|c|c|c|c|c|c|c|}
\hline \multirow{2}{*}{$\mathrm{N}^{\mathrm{o}}$} & \multicolumn{3}{|c|}{ BAIA } & \multirow{2}{*}{ TEUs } & \multicolumn{2}{|c|}{ CONSTRUÇÃO } & \multicolumn{3}{|c|}{ BUSCA LOCAL } & \multicolumn{3}{|c|}{ ILS } \\
\hline & $\mathrm{Q}$ & \begin{tabular}{l|l}
$\mathrm{L}$ \\
\end{tabular} & $\mathrm{H}$ & & CUSTO & TEMPO & CUSTO & $\%$ & TEMPO & CUSTO & $\%$ & TEMPO \\
\hline 1 & 12 & 5 & 10 & 600 & 1389 & 0 & 983 & $29 \%$ & 6,98 & 904 & $35 \%$ & 154,96 \\
\hline 2 & 12 & 7 & 10 & 840 & 1863 & 0 & 1346 & $28 \%$ & 14,65 & 1292 & $31 \%$ & 329,15 \\
\hline 3 & 12 & 10 & 10 & 1200 & 3044 & 0 & 2263 & $26 \%$ & 28,98 & 2153 & $29 \%$ & 681,28 \\
\hline 4 & 12 & 5 & 13 & 780 & 1984 & 0 & 1444 & $27 \%$ & 12,54 & 1319 & $34 \%$ & 295,09 \\
\hline 5 & 12 & 7 & 13 & 1092 & 2490 & 0 & 1903 & $24 \%$ & 24,71 & 1714 & $31 \%$ & 549,85 \\
\hline 6 & 12 & 10 & 13 & 1560 & 3293 & 0 & 2335 & $29 \%$ & 42,95 & 2276 & $31 \%$ & 975,61 \\
\hline 7 & 12 & 5 & 15 & 900 & 1974 & 0 & 1618 & $18 \%$ & 17,32 & 1554 & $21 \%$ & 392,81 \\
\hline 8 & 12 & 7 & 15 & 1260 & 3628 & 0 & 2860 & $21 \%$ & 38,78 & 2662 & $27 \%$ & 838,45 \\
\hline 9 & 12 & 10 & 15 & 1800 & 3140 & 0 & 2380 & $24 \%$ & 59,56 & 2347 & $25 \%$ & 1339,32 \\
\hline 10 & 16 & 5 & 10 & 800 & 1098 & 0 & 802 & $27 \%$ & 11,26 & 794 & $28 \%$ & 251,96 \\
\hline 11 & 16 & 7 & 10 & 1120 & 2250 & 0 & 1668 & $26 \%$ & 23,07 & 1519 & $32 \%$ & 538,18 \\
\hline 12 & 16 & 10 & 10 & 1600 & 2333 & 0 & 1596 & $32 \%$ & 39,67 & 1556 & $33 \%$ & 884,37 \\
\hline 13 & 16 & 5 & 13 & 1040 & 2171 & 0 & 1600 & $26 \%$ & 22,81 & 1530 & $30 \%$ & 505,17 \\
\hline 14 & 16 & 7 & 13 & 1456 & 3471 & 0 & 2758 & $21 \%$ & 45,59 & 2646 & $24 \%$ & 1074,76 \\
\hline 15 & 16 & 10 & 13 & 2080 & 5940 & 0 & 4551 & $23 \%$ & 98,82 & 4277 & $28 \%$ & 2296,87 \\
\hline 16 & 16 & 5 & 15 & 1200 & 3187 & 0 & 2457 & $23 \%$ & 29,31 & 2247 & $29 \%$ & 686,4 \\
\hline 17 & 16 & 7 & 15 & 1680 & 2487 & 0 & 1904 & $23 \%$ & 47,46 & 1894 & $24 \%$ & 1050,53 \\
\hline 18 & 16 & \begin{tabular}{|l|}
10 \\
\end{tabular} & \begin{tabular}{|l|}
15 \\
\end{tabular} & 2400 & 5740 & 0 & 4364 & $24 \%$ & 128,78 & 4101 & $29 \%$ & 2868,2 \\
\hline
\end{tabular}




\section{Conclusões}

Neste trabalho foi desenvolvida uma heurística ILS para a resolução do problema de carregamento e descarregamento de contêineres em navios, no qual objetiva-se realizar um número mínimo de remanejos. Experimentos computacionais foram realizados sobre 54 problemas testes, nos quais o método proposto foi comparado com um método construtivo e com um método de descida (método construtivo seguido de busca local). Os resultados obtidos destacam uma melhora média de $29 \%$ na qualidade das soluções quando comparado com o método construtivo e de $5 \%$ em relação ao método de descida. Isso demonstra a adequação da heurística ILS proposta ao problema abordado.

\section{Agradecimentos}

Este trabalho foi financiado pelo Conselho Nacional de Desenvolvimento Científico e Tecnológico (CNPq) e pela Fundação de Amparo à Pesquisa do Estado do Rio de Janeiro (FAPERJ).

\section{Referências}

AVRIEL, M.; PENN, M.; SHPIRER, N. (2000) "Container ship stowage problem: complexity and connection to the coloring of circle graphs". Discrete Applied Mathematics, v. 103, p. 271-279.

AZEVEDO, A. T.; SOBRAL, C. M.; DEUS, N. M. R. (2009) "Resolução do problema de carregamento e descarregamento de contêineres em terminais portuários via Algoritmo genético", XVI SIMPEP.

BERTOLANI, A. D.; LEME, F. L. (2004) "Carregamento de contêineres em navios. Universidade Presbiteriana Mackenzie".

CAMPOS, D.S. (2008) "Integração dos problemas de carregamento e roteamento de veículos com janela de tempo e frota heterogênea". 119p. Tese (Doutorado em Engenharia de Produção) - Universidade de São Paulo, São Paulo - SP.

GÓES, H. A. (2002) "Planejamento portuário". Rio de janeiro - Escola de Engenharia, Universidade Federal do Rio De Janeiro.

JÚNIOR, L. O. J.; ARROYO, J. E. C; SOUZA, V. A. A. (2009) "Heurísticas GRASP e ILS para o problema no-wait flowshop scheduling multiobjetivo", XLII SBPO.

LOURENÇO, H. R.; MARTIN, O. E STUETZLE, T. (2002) "Iterated local search", Handbook of Metaheuristics, p. 321-353, Norwell, MA. Kluwer Academic Publishers.

MARTINS, P. T.; LOBO, V. J. A. S.; VAIRINHOS, V. (2009) "Container Stowage Problem Solution for Short Sea Shipping", $14^{\circ}$ congresso da APDIO.

MESQUITA, A.C.P. (2010) "A metaheurística busca dispersa em problemas de roteirização de veículos com coleta e entrega simultâneas: aplicação na força aérea brasileira”. 103p. Dissertação (Mestrado em Engenharia) - Escola politécnica da Universidade de São Paulo, São Paulo - SP.

MORABITO, R.; ARENALES, M. (1997) "Abordagens para o problema do carregamento de contêineres". Pesquisa Operacional, 17 (1), 29-56. 
MOTA, L. C. S. ; OCHI, L. S. (2009) "Metaheurísticas com memória adaptativa para o problema de recobrimento de rotas", IX Congresso Brasileiro de Redes Neurais.

NOGUEIRA, R. T.; JR, G. G. P.; PÓVOA, C. L. R. (2006) "Uma heurística GRASP para o problema do pequeno investidor", XIII SIMPEP.

RAIDL, G. R. (1999) “A weight-coded genetic algorithm for the multiple container packing problem", 14th ACM Symposium on Applied Computing.

SOBRAL, C. M.; AZEVEDO, A. T.; LIMA, F. M. B. (2009) "Resolução do problema de carregamento e descarregamento de contêineres em terminais portuários via Beam Search", XVI SIMPEP.

SOUZA FILHO, G.F. (2008) "Metaheurísticas sequencias e paralelas para a configuração de um serviço de distribuição de vídeo digital ao vivo". 86p. Dissertação (Mestrado em Informática) - Universidade Federal da Paraíba, João Pessoa - PB..

TEMPONI, E.C.C. (2007) "Uma proposta de resolução do problema de corte bidimensional via abordagem metaheurística". 100p. Dissertação (Mestrado em modelagem matemática computacional) - Centro Federal de Educação Tecnológica de Minas Gerais, Belo Horizonte- MG.

WILSON, I. D., ROACH, P. A. (2000) “Container Stowage Planning: A methodology for generating computerised solutions". Journal Of The Operational Research Society. 